\title{
The fiscal expenditure efficiency of China's rural compulsory education
}

\author{
Suli Hao ${ }^{1, a}$ and Nan Zhang ${ }^{1, b}$ \\ ${ }^{1}$ School of Management, China University of Mining and Technology (Beijing) BeiJing, P.R.China \\ asluckylh@126.com, b40062686@qq.com
}

Keywords: Fiscal expenditure efficiency, Rural compulsory education, DEA model, Empirical analysis.

\begin{abstract}
Effective of fiscal expenditure is the key to equalization of China's rural compulsory education. The paper takes the efficiency of China's rural compulsory education as the object. By applying EVA, the indicator system and evaluation model of fiscal expenditure efficiency is established. In addition 31 provinces and autonomous regions of China in 2009-2012 were selected as sample data to validate the fiscal expenditure efficiency of China's rural compulsory education. And then the paper develops a strategy for dealing with problems that would improve the fiscal expenditure efficiency of China's rural compulsory education.
\end{abstract}

\section{Introduction}

With the continuous development of economic and social progress, the level of infrastructure construction was improved. And the public service system was basically established. "13th Five-Year Plan" clearly pointed out that it is necessary to strong public service system such as education and employment. In addition it is very important to promote educational equity and accelerate the construction of compulsory education in urban and rural areas. But whether the financial investment of government is effectively achieved its desired objectives has been the main concern of the government. Therefore lots of scholars carried out the research on the fiscal expenditure efficiency of china rural compulsory education. Steven Bradley, Geraint Johnes, Jim Millington applied the DEA-Tobit model to measure the input-output effect of the English middle school in 1993-1998[1]. Takako Yuki toke yemen as an example to analyze the public education spending by using standard profit margins. [2] Rouselle F. Lavado, Emilyn C. Cabanda applied the DEA model to study the efficiency of education and health expenditure in the provinces and cities of the Philippines[3]. Kalyan Chakraborty,Vincent C.Blackburn applied the two-stage EDA and efficiency model to study the low cost of government schools in New South Wales Australia[4]. Stephen J.Conroya, Nestor M.Arguea applied the marginal production function to analyze whether Florida primary school operations were effective and explain their ineffective reasons[5]. Dobdinga C. Fonchamnyo, Molem C. Samaapplied DEA-Tobit and Logit regression model to analyze the efficiency education and medical public expenditure by taking into account institutional and economic factors impac[6]t. LeoŠ Vítek, Lenka Martínková designed the indicators from economy, efficiency and effectiveness. And the paper established model to evaluate the primary education expenditure projects in the Czech Republic. [7] Li Ling, Yan deming and Huang chen applied DEA-Malmquist model to study the efficiency of rural compulsory education allocation in eastern, central and western China[8]. Luo fang, Ma weimin applied malmquist-OLS two-stage method to measure the basic educational financial input efficiency of 12 cities in Huber Province, and then use the panel data model to analyze the influencing factors of fiscal expenditure efficiency[9].

\section{Establish the evaluation indicator system}

\subsection{The fiscal expenditure efficiency}

Public finance expenditure is refers that the government provides public services and products to 
meet the common needs of the community to carry out the payment of financial. It contains two meanings: one is what public services and products could be improved to fulfill the functions of the government. And the other is how to make the distribution of the expenditure proportion and expenditure structure (that is effective).Based on the evaluation method of government expenditure efficiency, the evaluation method of general education expenditure can be divided into three categories: comprehensive indicator system evaluation, frontier efficiency analysis and DEA method. The comprehensive indicator system evaluation and DEA method is applied to evaluate the fiscal expenditure efficiency of China rural compulsory education.

\subsection{The indicator system}

Combined with the characteristics of rural compulsory education fiscal expenditure efficiency, this paper selects 5 input indicators and 4 output indicators as indicators of rural compulsory education fiscal expenditure efficiency. Furthermore the data sources of each indicator are given.

(1) Input indicator

Salary and welfare expenditure(X1): the indicator is used to reflect the total remuneration expenditure of staff and temporary workers in rural primary schools and the social security fees stipulated by the state.

Subsidies to individuals and families(X2): the indicator refers to government subsidies to farmers and rural families.

Expenditure on goods and services(X3): the indicator is used to reflect the school expenditure of the labor goods and services. But the commodity category does not include the cost of being classified as fixed assets.

The other capital expenditures(X4): the indicator refers to the non-development and reform departments financial expenditure that is use to purchase fixed assets, land, intangible assets, and build infrastructure construction and large repairs for the rural primary school and middle school.

The infrastructure expenditure(X5): the indicator refers to the non-public financial budget special funds that use to purchase fixed assets, intangible assets, infrastructure and large repair for primary school and middle school. And the fund excludes public finance budget matching funds.

(2) Output indicator

Full-time teacher and students rate (Y1): The full-time teachers and students rate $=$ the number of full-time teachers / number of students in school $* 100 \%$

Stability rate (Y2): Stability rate $=$ number of graduates $/$ enrollment $* 100 \%$

New additional school building area rate (Y3): New additional school building area rate $=$ number of new additional school building area / the total area of the school building * $100 \%$

Educational Instrument and fixed assets rate (Y4): Educational instrument and fixed assets rate $=$ educational instrument value / total fixed assets * $100 \%$

In summary, the evaluation indicator system of the china's rural compulsory education fiscal expenditure efficiency is establishment. And it shows in table 1.

Table.1 The evaluation indicator system of rural compulsory education fiscal expenditure efficiency

\begin{tabular}{ll}
\hline & $\left(\mathrm{X}_{1}\right)$ Salary and welfare expenditure \\
& $\left(\mathrm{X}_{2}\right)$ Subsidies to individuals and families \\
Input indicators & $\left(\mathrm{X}_{3}\right)$ Expenditure on goods and services \\
$(1)$ & $\left(\mathrm{X}_{4}\right)$ The other capital expenditures \\
& $\left(\mathrm{X}_{5}\right)$ The infrastructure expenditure \\
\hline & $\left(\mathrm{Y}_{1}\right)$ Full-time teacher and students rate \\
Output indicators & $\left(\mathrm{Y}_{2}\right)$ Stability rate \\
$(2)$ & $\left(\mathrm{Y}_{3}\right)$ New additional school building area rate \\
& $\left(\mathrm{Y}_{4}\right)$ Educational Instrument and fixed assets rate \\
\hline
\end{tabular}




\section{The method}

\subsection{The model selected}

Date envelopment analysis (DEA) is a evaluation efficiency method that is comparison of the performance of multiple inputs and multiple outputs with multiple decision units of the same or similar external environment in the activities. It was first proposed by A. Charnes, W.W. Cooper, and Rhodes (E.Rhodes) in 1978. DEA method has two basic models: C2R model and BC2 model. The difference between the two models is that the different assumptions of the scale pay. The C2R model assumes that the scale pay is fixed and the BC2 model assumes variable returns to scale. Taking into account the characteristics of the relationship between financial investment change of rural compulsory education and the change of output, BC2 model is more realistic. Therefore BC2 model is applied to analyze the efficiency of rural compulsory education.

\subsection{The model design}

Number of symbols would be applied to build the DEA model. So firstly the various symbols are explained.The object of research is the decision-making unit (DMU), so j represents the jth DMU. 31 DMUs are evaluated in this paper, so $j=1,2, \cdots, 31$. The hj represents the efficiency number of the jth DMU.The $m$ represents the number of input variables in the model. And s represents the number of output variables. There are 5 input indicators in this paper. So $m=1,2, \cdots, 5$. There are 5 output indicators. So $s=1,2, \cdots, 5$.xij represents ith input of jth DMU. And $x i j>0$. The vi is the weight of ith input. And $i=1,2, \cdots$, 5.The yrj represents rth output of jth DMU. And yrj $>0$. The ur is the weight of rth output. And $r=1,2, \cdots, 5$.

The hj represents performance evaluation index of every DMU. And the formula is:

$$
h_{j}=\frac{u^{T} Y_{j}}{v^{T} X_{J}}=\frac{\sum_{r=1}^{s} u_{r} y_{r j}}{\sum_{i=1}^{m} v_{i} x_{i j}}
$$

In which, $X_{j}=\left(x_{1 j}, x_{2 j}, \cdots, x_{m j}\right)^{T}, Y_{j}=\left(y_{1 j}, y_{2 j}, \cdots, y_{s j}\right)^{T}, j=1,2, \cdots, 31$.

By selecting the appropriate coefficients $\mathrm{u}$ and $\mathrm{v}$, and

$0 \leqslant h_{j} \leqslant 1, j=1,2, \cdots, 31$.

The $\mathrm{C}^{2} \mathrm{R}$ model is applied to evaluate the efficiency of rural compulsory education. The linear programming formula of the computational efficiency extreme is as follow:

$$
\operatorname{maxh}_{\mathrm{j} 0}=\frac{\mathrm{u}^{\mathrm{T}} \mathrm{Y}_{\mathrm{j} 0}}{\mathrm{v}^{\mathrm{T}} \mathrm{X}_{\mathrm{J} 0}}=\frac{\sum_{\mathrm{r}=1}^{\mathrm{s}} \mathrm{u}_{\mathrm{r}} \mathrm{y}_{\mathrm{rj} 0}}{\sum_{\mathrm{i}=1}^{\mathrm{m}} \mathrm{v}_{\mathrm{i}} \mathrm{X}_{\mathrm{ij} 0}} \quad \text { (2) }\left\{\begin{array}{c}
0 \leq \mathrm{h}_{\mathrm{j} 0} \leq 1 \\
\mathrm{u}=\left(\mathrm{u}_{1}, \mathrm{u}_{2}, \cdots \mathrm{u}_{\mathrm{s}}\right)^{\mathrm{T}} \geq 0 \\
\mathrm{v}=\left(\mathrm{v}_{1}, \mathrm{v}_{2}, \cdots \mathrm{v}_{\mathrm{m}}\right)^{\mathrm{T}} \geq 0
\end{array}\right.
$$

Corresponding to the dual form as follows:

$$
\min \left[\theta-\varepsilon\left(\sum_{\mathrm{i}=1}^{\mathrm{m}} \mathrm{s}_{\mathrm{i}}^{-}+\sum_{\mathrm{r}=1}^{\mathrm{s}} \mathrm{s}_{\mathrm{r}}^{+}\right)\right]
$$

$$
\text { s.t. }\left\{\begin{array}{c}
\sum_{j=1}^{t} x_{j} \lambda_{j}+s_{i}^{-}=\theta x_{0} \\
\sum_{j=1}^{t} y_{j} \lambda_{j}-s_{r}^{+}=y_{0} \\
\sum_{j=1}^{t} \lambda_{j}=1 \\
\lambda_{j} \geq 0, \quad j=1,2, \quad \ldots, 31 \\
s_{i}^{-} \geq 0, \quad s_{r}^{+} \geq 0
\end{array}\right.
$$

Among them, $\theta$ is a pure technical efficiency of a selected decision making unit $\mathrm{DMU}_{0} . \quad \theta \in$ $[0,1]$, the bigger the value of $\theta$, the closer to 1 , means the higher efficiency, the better the performance. 
$\varepsilon$ is Archimedes infinitesimal.

$\lambda_{\mathrm{j}}$ is a combination ratio of No.j decision making unit of DMU combination. And bound by conditions: $\quad \sum_{j=1}^{t} \lambda_{j}=1$.

$\mathrm{s}^{+}, \mathrm{s}^{-}$are slack variables. Its economic meanings respectively:

(1) When $\theta=1$ and $s^{-}=s^{+}=0, D_{0}$ is DEA effective. Namely in a system of $\mathrm{j}$ decision making units, input $\mathrm{X}_{0}$ and output $\mathrm{Y}_{0}$ have reached optimal.

(2) When $\theta=1$ and $s^{-} \neq 0$ or $s^{+} \neq 0$, DMU0 is weak DEA effective. Namely in a system of $j$ decision making units, input $\mathrm{X}_{0}$ can decrease s- while the output $\mathrm{Y}_{0}$ unchanged, or output $\mathrm{Y}_{0}$ can increase $\mathrm{s}^{+}$and keep input $\mathrm{X}_{0}$ unchanged;

(3) When $\theta<1, \mathrm{DMU}_{0}$ is invalid DEA. In a system composed of $\mathrm{j}$ decision making units, by adjusting $\mathrm{X}_{0}$ the proportion of $\theta$ and keep the original output $\mathrm{Y}$ no decrease.

By using $\mathrm{BC}^{2}$ model, can be in the $\mathrm{C}^{2} \mathrm{R}$ model on the basis of analysis of scale efficiency, and also can analyze the lack or redundancy of input and output.

\section{The data}

\subsection{The division of DMU}

The premise of DEA is clearly the DMU of evaluation. The 31 provinces are selected as the DMUs, and 2009-2012 data as the sample to analyze the efficiency of each DMU. Finally, according to the efficiency of DMU the regional differences rural compulsory education fiscal expenditure efficiency are summed up.

\subsection{The data sources}

As the lack of data of the "China Education Funds Statistical yearbook" and "China Education Statistics Yearbook" in 2013 and 2014, the relevant input-output data for 2009-2012 four years data were selected as a sample to research the fiscal efficiency of rural compulsory education. All of the samples are from the "China Education Fund Statistical Yearbook" and "China Education Statistical Yearbook". And all of the indicators are positive indicators.

\subsection{Analysis of fiscal expenditure efficiency}

The DEA model is applied to analyze the pure technical efficiency of 29 provinces. The non-directional methods (not limited to input and output and can be adjusted) is applied to quantitative analyze. The wage benefits, subsidies for individuals and families, goods and services, other capital expenditures and construction investments are been as input indicators. And expansion 10000 times of the full-time teachers and students ratio, consolidation rate, New additional school building area rate and Educational Instrument and fixed assets rate as the output indicators. All calculations are done through the MaxDEA Ultra 6.8 software and Excel to complete the data collation. And the data are showed in table 2.

The above table shows that the technical efficiency of rural elementary school compulsory education is lower in 2009-2012. The average value is the highest in 2012. And it is 0.65. The average value is the lowest in 2009, and it is 0.55 . And the overall trend of scale efficiency is fluctuating. Most of the provinces of elementary education compulsory education fiscal investment in technology and scale are "non-effective". And this means that the inefficiency of investment and the efficiency of investment scale are not the optimal. Based on the analysis results of the two efficiencies, it can be seen that the reason for the low efficiency of technology is due to the low efficiency of both economies of scale and pure technology. In summary, the scale efficiencies of eastern and western regions are higher than the middle efficiency. But the overall technical level is lower. 
Table. 2 The provincial rural primary school's annual technical efficiency value comparison table from 2009 to 2012

\begin{tabular}{c|c|c|c|c|c|c|c|c|c|c|c}
\hline \multicolumn{10}{c}{} & \multicolumn{10}{c}{ Pure Technical Efficiency Score(PTE) } & \multicolumn{1}{c}{ DMU } & 2009 & 2010 & 2011 & 2012 \\
\hline Beijing & 01 & 1.00 & 1.00 & 1.00 & 1.00 & Hubei & 17 & 0.32 & 0.41 & 0.34 & 0.51 \\
\hline Tianjin & 02 & 1.00 & - & 1.00 & 1.00 & Hunan & 18 & 0.20 & 0.33 & 0.27 & 0.28 \\
\hline Hebei & 03 & 1.00 & 0.39 & 0.24 & 0.20 & Guangdong & 19 & 0.19 & 0.43 & 0.45 & 0.34 \\
\hline Shanxi & 04 & 1.00 & 1.00 & 0.52 & 0.79 & Guangxi & 20 & 0.26 & 0.39 & 0.29 & 0.32 \\
\hline InnerMongolia & 05 & 1.00 & 1.00 & 0.89 & 1.00 & Hainan & 21 & 1.00 & 1.00 & 1.00 & 1.00 \\
\hline Liaoning & 06 & 0.34 & 1.00 & 0.81 & 1.00 & Chongqing & 22 & 0.56 & 1.00 & 0.57 & 0.72 \\
\hline Jilin & 07 & 1.00 & 1.00 & 0.95 & 1.00 & Xichuan & 23 & 0.27 & 0.39 & 0.13 & 0.17 \\
\hline Heilongjiang & 08 & 0.88 & 1.00 & 1.00 & 1.00 & Guizhou & 24 & 0.28 & 0.51 & 0.70 & 0.69 \\
\hline Shanghai & 09 & - & - & - & - & Yunnan & 25 & 0.30 & 0.57 & 0.21 & 0.32 \\
\hline Jiangsu & 10 & 0.17 & 0.23 & 0.21 & 1.00 & Tibet & 26 & 1.00 & 1.00 & 1.00 & 1.00 \\
\hline Zhejiang & 11 & 0.15 & 0.46 & 0.38 & 0.37 & Shanxi & 27 & 0.30 & 0.25 & 0.57 & 0.59 \\
\hline Anhui & 12 & 0.17 & 0.33 & 0.22 & 0.22 & Gansu & 28 & 0.33 & 0.30 & 0.46 & 0.47 \\
\hline Fujian & 13 & 0.33 & 0.43 & 0.37 & 0.36 & Qinghai & 29 & 1.00 & 1.00 & 0.91 & 1.00 \\
\hline Jiangxi & 14 & 0.27 & 0.43 & 0.26 & 0.26 & Ningxia & 30 & 1.00 & 1.00 & 1.00 & 1.00 \\
\hline Shandong & 15 & 0.18 & 0.69 & 1.00 & 1.00 & Xinjiang & 31 & 0.81 & 0.36 & 0.62 & 0.58 \\
\hline Henan & 16 & 0.15 & 0.27 & 0.24 & 0.34 & Average & 32 & 0.55 & 0.63 & 0.59 & 0.65 \\
\hline
\end{tabular}

\section{Result analysis}

According to the analyzing results of DEA, it can be improved for each DMU that technical efficiency is not 1 . Due to the redundancy in the decreasing of scale, it should be reduced the input to improve the technical efficiency and make it more close to the frontier. For each input or output can be improved the proportion and relaxation. The sum of two is all improved. The DUM can be achieved frontier after the above is improved. The result shows that the input and output of rural elementary schools in different regions of China is relatively in 2012. There are 14 provinces that relaxations are 0 . They need not to be improved. In 2012, in the case of maximizing output, the salary and welfare expenditure redundancies of Jiangxi rural elementary schools are 3.3 billions. And the personal and family subsidy expenditure should be reduced by 84.289 millions. The goods and services expenditure should be reduced by 1032674 thousands. The other capital expenditure should be reduced by 1429537 thousands. The construction expenditure should be reduced by 89599 thousands. The input will reach the frontier. Furthermore under the established size of the input, the full-time teachers and students should increase 1.5 times. Stability rate should increase 1.6 times. New additional school building area rate should increase 2 times. Educational Instrument and fixed assets rate should increase 3.4 times. The output will reach the frontier.

The empirical results show that the overall expenditure on compulsory education in rural elementary schools was higher in the past four years. It can be show in the figure 1.

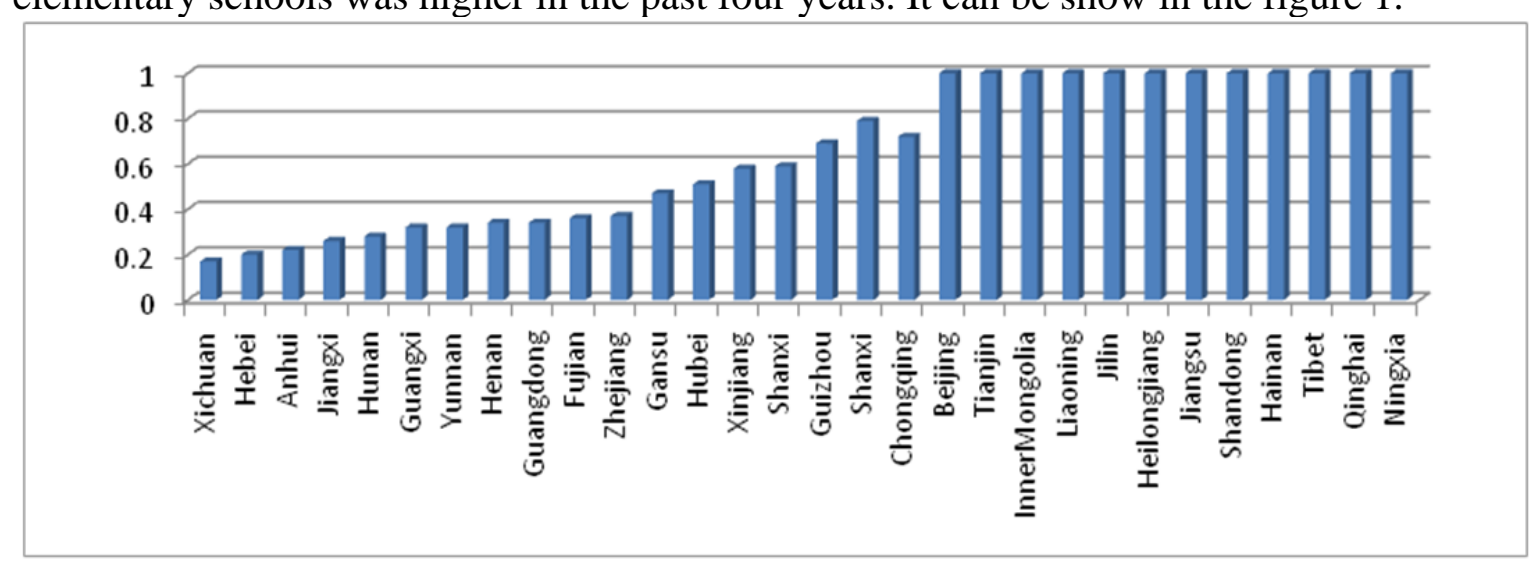

Fig. 1 the provincial countryside primary school's technical efficiency sorting chart in 2012

The low efficiency of technology in most areas is mainly due to the relatively low efficiency of the two multipliers. 


\section{Discussion}

In view of the weak rural compulsory education in China, the uneven development level and the low scale efficiency the paper puts forward the following financial support suggestion.

1) Increase financial input to ensure that the level of investment in rural compulsory education. The compulsory education funds sharing mechanism can be established based on the compulsory education level. And the local government should ensure the teacher salaries, the central government should ensure the construction funds.

2) Clarify the responsibilities and the proportion of funds sharing between local government and central government in the supply of rural compulsory education. The county government should establish a demand budget and have a compulsory education planning based on the regional situation and determine the demand of education expenditure. The local government should allocate compulsory education funding based on the proportion of fiscal revenue to ensure long-term stability of education funds. And the central government should play a major regional capacity, and improve the standardization of compulsory education financial transfer payment system.

3) strengthen the sharing mechanism of educational resources between provinces and improve the efficiency of rural compulsory education. It is necessary to clarify the responsibilities of rural compulsory education expenditure in various regions and share resources-rich areas to resource-scarce areas to balance the educational resources between provinces. Furthermore the horizontal and financial transfer payment system must be established to flow the resources between provinces.

4) Improve the compulsory education performance evaluation system. The evaluation indicators system need to be established to evaluated the education expenditure efficiency. And the evaluation content, duration and object must be clarified. Furthermore the evaluation staff qualification is need to be identified.

\section{References}

[1] Steven Bradley,Geraint Johnes,Jim Millington.The effect of competition on efficiency of secondary schools in England[J].European Journal of Operational Research,2001,135:545-568.

[2] Takako Yuki,Distribution of Public Education Spending for the Poor:The Case of Yemen[J].Asia Pacific Education Review,2003,Vol.4,No.2:129-139.

[3] Rouselle F. Lavado, Emilyn C. Cabanda,The efficiency of health and education expenditures in the Philippines[J].Central European Journal of Operations Research,2009,Volume 17,Issue $3: 275-291$.

[4] Kalyan Chakraborty,Vincent C.Blackburn,Efficiency and Equity in Funding for Government Schools in Australia[J].Australian Economic Papers,2013,52(3-4):127-142.

[5] Stephen J.Conroya, Nestor M.Arguea,An estimation of technical efficiency for Florida public elementary schools[J].Economics of Education Review,2008,27(6):655-663.

[6] Dobdinga C. Fonchamnyo,Molem C. Sama,Determinants of public spending efficiency in education and health: evidence from selected CEMAC countries[J].Journal of Economics \& Finance, 2014:1-12

[7] LeoŠ Vítek,Lenka Martínková,Assessment of Efficiency of Expenditure Programmes in Education: Primary Education in the Czech Republic[J].Procedia Economics \& Finance, 2015,25:607-614.

[8] Li Ling, Yan deming and Huang chen. Researched on the Efficiency Allocation of Rural Compulsory Education in China--- An Empirical Analysis Based on DEA and Malmquist Index. [J]. Education and Economy,2014,03:3-7+15. 
[9] Luo fang, Ma weimin. The Effect of Fiscal Decentralization on the Efficiency of Financial Expenditure of Basic Education--- Based on Malmquist-OLS two-stage method [J]. Journal of Huanggang Normal University,2015,01:1-6+118. 